\title{
Cellular engineering and biocatalysis strategies toward sustainable cadaverine production: State of the art and perspectives
}

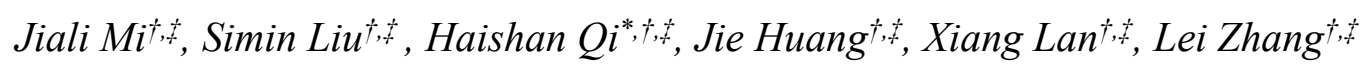

†Department of Biochemical Engineering, School of Chemical Engineering and Technology, Tianjin University, No.135, Yaguan Road, Tianjin 300072, P.R. China.

$\$$ School of Chemical Engineering and Technology, Frontier Science Center for Synthetic Biology and Key Laboratory of Systems Bioengineering (MOE), Tianjin University, No.135, Yaguan Road, Tianjin 300350, P. R. China.

*Corresponding author:

Haishan Qi, e-mail: hsqi@tju.edu.cn. 
Table S1 Comparison of the mechanical properties of petrochemical PA 6, PA 66 and bio-based PA 510.

\begin{tabular}{|c|c|c|c|}
\hline \multirow[t]{2}{*}{ Property } & \multicolumn{3}{|c|}{ Pure } \\
\hline & PA 6 & PA 66 & PA 510 \\
\hline Bio-based content [\%] & 0 & 0 & 100 \\
\hline Viscosity number $\left[\mathrm{mL} \mathrm{g}^{-1}\right]$ & 150 & 150 & 141 \\
\hline Melting point $\left[{ }^{\circ} \mathrm{C}\right]$ & 220 & 260 & 215 \\
\hline Glass transition temperature $\left[{ }^{\circ} \mathrm{C}\right]$ & 54 & 60 & 50 \\
\hline Density $\left[\mathrm{g} \mathrm{cm}^{-3}\right]$ & 1.14 & 1.14 & 1.07 \\
\hline Water absorption $[\%]$ & 3 & 2.8 & 1.8 \\
\hline \multirow[t]{2}{*}{ Haze } & 102 & 102 & 64 \\
\hline & $30 \%$ glass & itent (b & $3^{\circ} \mathrm{C}$ dry) \\
\hline Tensile strength $[\mathrm{MPa}]$ & 179 & 188 & 155 \\
\hline Elongation at break [\%] & 3.8 & 3.7 & 3.9 \\
\hline E-modulus [MPa] & 9424 & 9586 & 8310 \\
\hline Impact strength, notched $\left[\mathrm{kJ} \mathrm{m}^{-2}\right]$ & 15 & 10 & 12 \\
\hline Impact strength, unnotched $\left[\mathrm{kJ} \mathrm{m}^{-2}\right]$ & 99 & 83 & 86 \\
\hline
\end{tabular}

Data from previously published paper. ${ }^{20}$ 


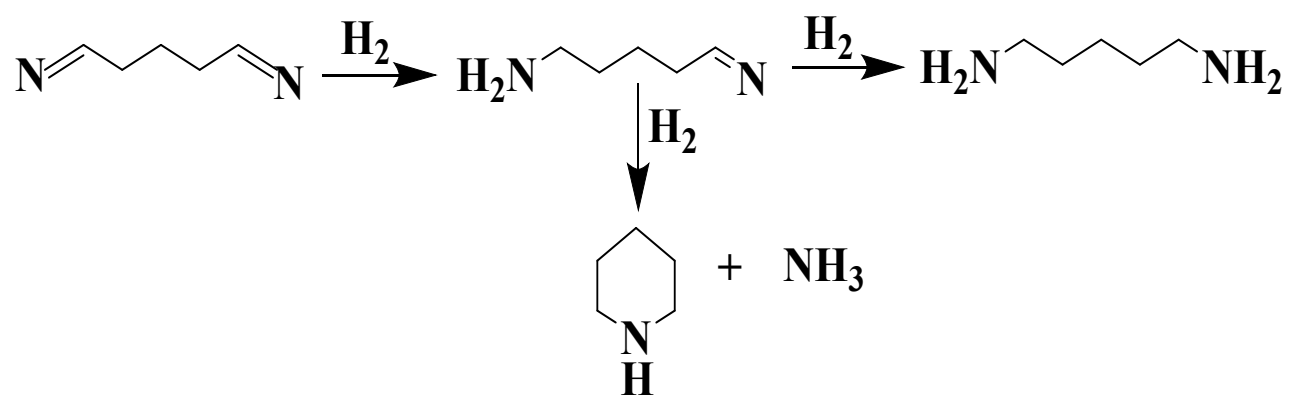

Figure S1. Cadaverine synthesis with glutaronitrile hydrogenation. 


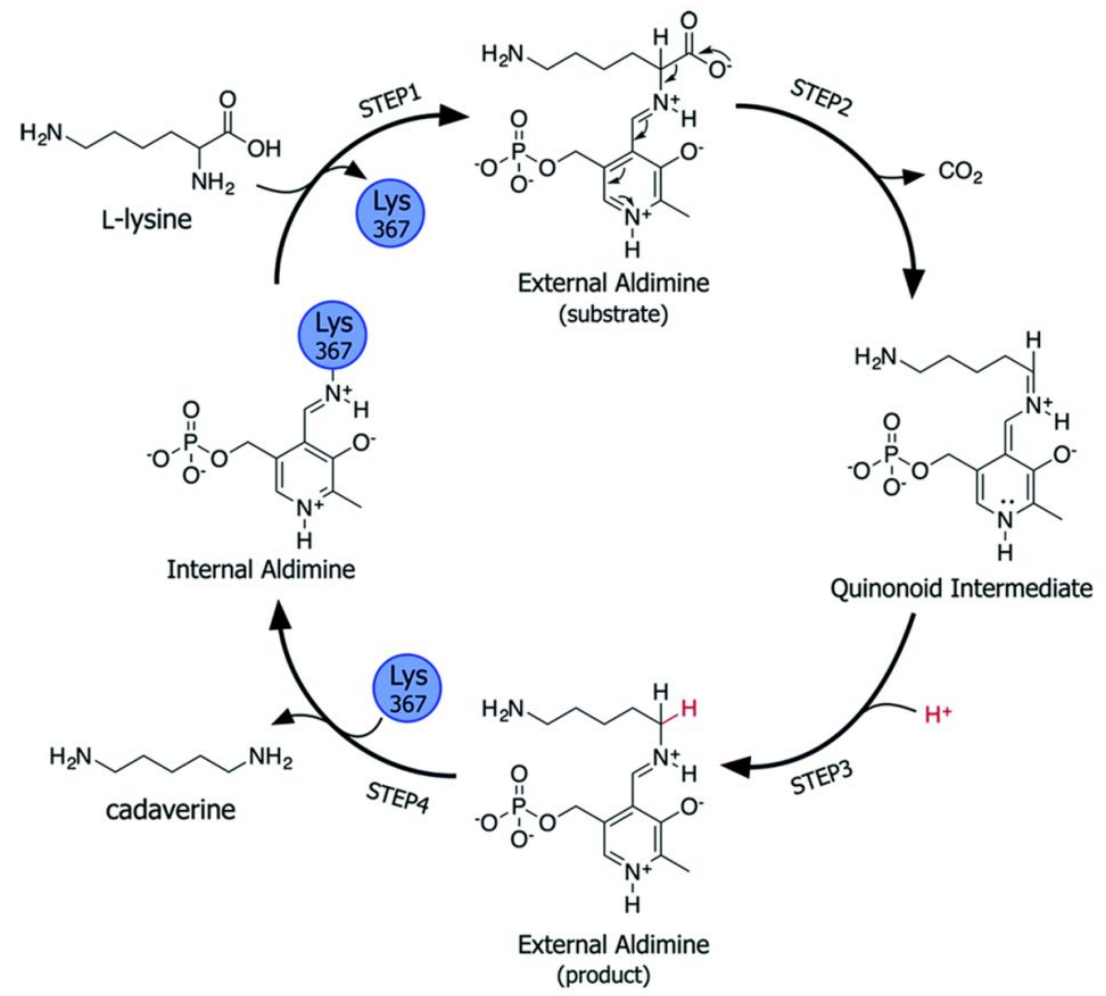

Figure S2. The suggested mechanism for lysine decarboxylase. 